\title{
Aqueous and ethanolic extract fractions from the Brazilian propolis suppress azoxymethane-induced aberrant crypt foci in rats
}

\author{
YUMIKO YASUI ${ }^{1}$, SHINGO MIYAMOTO ${ }^{2}$, MIHYE KIM ${ }^{1}$, \\ HIROYUKI KOHNO $^{1}$, SHIGEYUKI SUGIE ${ }^{1}$ and TAKUJI TANAKA ${ }^{1}$ \\ ${ }^{1}$ Department of Oncologic Pathology, Kanazawa Medical University, 1-1 Daigaku, \\ Uchinada, Ishikawa 920-0293; ${ }^{2}$ Division of Food Science and Biotechnology, \\ Graduate School of Agriculture, Kyoto University, Kyoto 606-8502, Japan
}

Received February 20, 2008; Accepted April 30, 2008

DOI: 10.3892/or_00000033

\begin{abstract}
We investigated the effects of the two fractions, aqueous (AEP) and ethanolic extracts of propolis (EEP) of the Brazilian propolis on azoxymethane (AOM)-induced aberrant crypt foci (ACF). Male Wistar Hannover (GALAS) rats were administered two weekly subcutaneous injections of AOM $(20 \mathrm{mg} / \mathrm{kg}$ bw) and fed with diets mixed with AEP (100, 500 and 1,000 ppm) or EEP (500 and 1,000 ppm) for 4 weeks, starting one week before the first dosing of AOM. The modifying effects of the test extracts on ACF formation were assessed by counting the incidence and multiplicity of ACF at week 4. Proliferation cell nuclear antigen (PCNA)-labeling nuclei and apoptotic index were also immunohistochemically determined. Dietary supplementation with AEP and EEP significantly reduced the multiplicity of ACF with the effect of EEP being more potent than AEP. In the ACF and their surrounding non-lesional crypts, significantly lowered cell proliferation was observed in the rats, administered with AOM, and the extracts, while neither fraction affected the apoptotic index. Our findings suggest that AEP and EEP possess a chemopreventive ability in the early phase of colon carcinogenesis through the modulation of cell proliferation.
\end{abstract}

Correspondence to: Dr Yumiko Yasui, Department of Oncologic Pathology, Kanazawa Medical University, 1-1 Daigaku, Uchinada, Ishikawa 920-0293, Japan

E-mail: y-yasui@kanazawa-med.ac.jp

Abbreviations: AEP, aqueous extract of propolis; EEP, ethanolic extract of propolis; AOM, azoxymethane; ACF, aberrant crypt foci; PCNA, proliferation cell nuclear antigen; CRC, colorectal cancer; EtOH, ethanol; ssDNA, single-stranded DNA

Key words: propolis, aqueous extract, ethanolic extract, chemoprevention, aberrant crypt foci, rats

\section{Introduction}

The high incidence of colorectal cancer (CRC) is a major public health problem in the United States and other Western countries (1). In Japan, the prevalence of CRC and the percentage of occurrence of this cancer among cancer deaths are increasing (2). Although the etiology of CRC development is multifactorial and complex, a great deal of effort has been made in the identification of naturally occurring and related synthetic agents that prevent CRC development. Numerous naturally occurring compounds such as phenols, indoles, inositol-6-phosphate, aromatic isothiocyanates and dithiolethiones were shown to inhibit several types of cancer, including $\mathrm{CRC}$, in preclinical studies using laboratory animal models $(3,4)$.

Propolis is a natural product that is derived from plant resins collected by honeybees. Propolis, used in folk medicine for centuries contains a variety of compounds including polyphenolics, flavones, flavonones, phenolic acid and esters, and fatty acids (5). Capillary zone electrophoresis revealed that different flavonoids, such as chrysin, rutin, catechin, myricetin, luteolin and quercetin, two phenolic acids (cinnamic and caffeic acids), and a stilbene derivative, resveratrol, are found in propolis extracts (6). The composition of the propolis depends upon the vegetation of the area from where it was collected and on the bee species. Brazilian propolis specifically contains artepillin $\mathrm{C}$, because the bees collect materials from the Brazilian plant, Baccharis dracunculifolia, which contains a large amount of antioxidative artepillin $\mathrm{C}(7,8)$. Propolis has a variety of biological activities. They include anticarcinogenic (9), antioxidative (10), anti-inflammatory (11) and antibiotic (12) activities. Propolis has attracted much attention in recent years as a potential substance used for medicine and cosmetics. Several studies have reported on the anticarcinogenic activity of propolis in the colon $(13,14)$. The active compounds of propolis are considered to be artepillin C (15) and caffeic acid (14), which are present in the ethanolic extract of propolis. Therefore, biological activities of the ethanolic rather than aqueous extract from propolis are attractive. However, few studies dealing with biological 


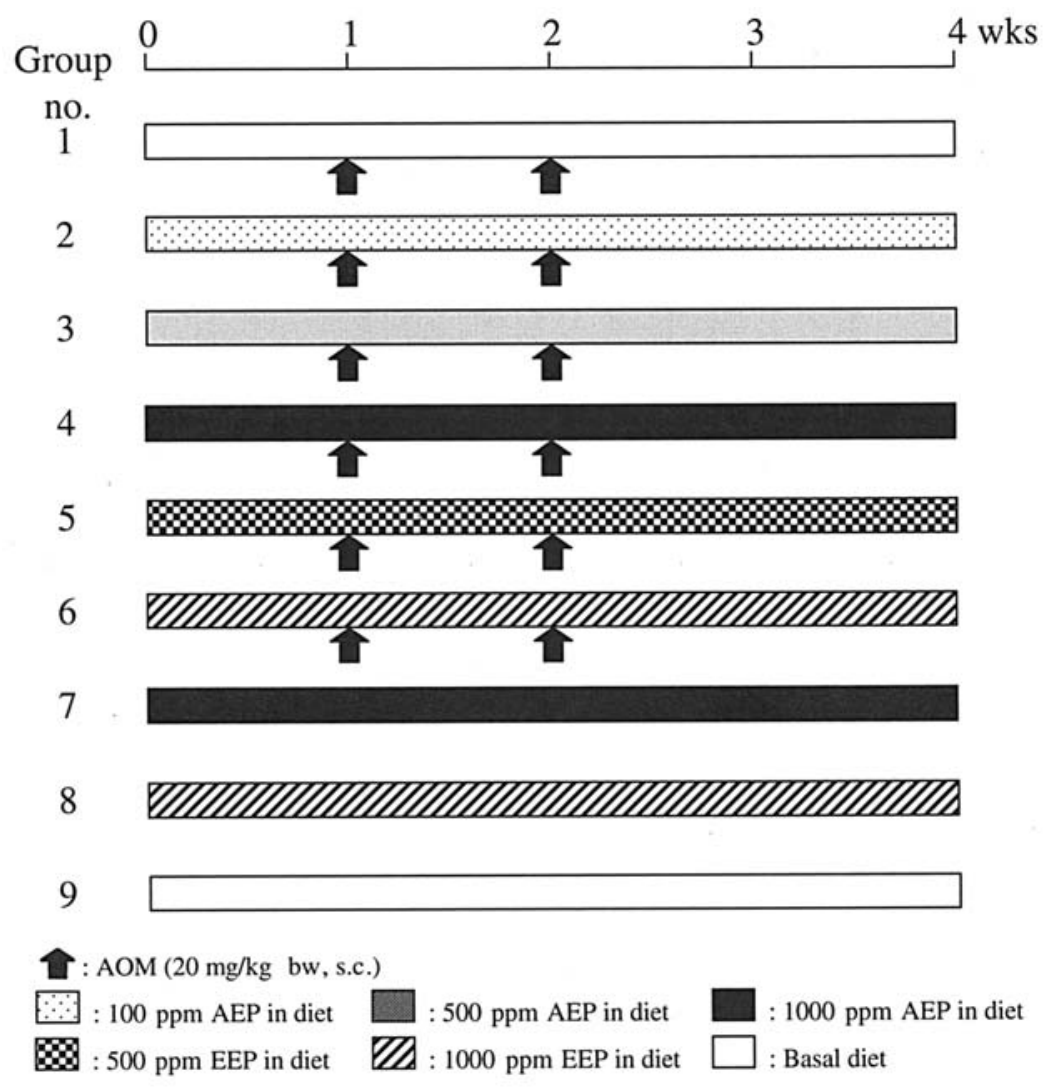

Figure 1. The experimental protocol.

activities, including the neuroprotective (16) and antimutagenic effects (17), of the aqueous extract of propolis exist.

In the present study, we determined whether the aqueous fraction from the Brazilian propolis extracts prevents the formation of aberrant crypt foci (ACF), which are a putative precursor lesion for CRC (18), induced by azoxymethane $(\mathrm{AOM})$ in the rat colon. The effects were compared with those of the ethanolic extract.

\section{Materials and methods}

Preparation of fractions from Brazilian propolis extracts. Brazilian propolis was obtained from the Yamada Apiculture Center (Okayama, Japan). Brazilian propolis (100 g) was extracted with $60 \%$ ethanol $(\mathrm{EtOH})$ at room temperature to yield the extract. The EtOH extract was filtrated, evaporated and lyophilized. $\mathrm{H}_{2} \mathrm{O}$ was added to the extracts, and then filtrated. The filtrate was lyophilized to give an aqueous fraction (AEP, $14 \mathrm{~g}$ ), and the residue was further extracted with EtOH to give an ethanolic fraction (EEP, $35 \mathrm{~g}$ ). AEP and EEP were identified using a Delta 600E system (Nihon Waters, Tokyo, Japan) equipped with a Waters 2996 photodiode-array detection system. The used column was Cosmosil 5C18-AR-II ( $\Phi 4.6 \times 250+\Phi 4.6 \times 20 \mathrm{~mm})$ (Nacalai Tesque Inc., Kyoto, Japan). The flow rate was $1 \mathrm{ml} / \mathrm{min}$. We then identified the ingredients in the fractions by $1 \mathrm{H}$ NMR spectroscopy (ECA600 spectrometer, JEOL Ltd., Tokyo, Japan) and MS analysis (SX102A spectrometer, JEOL Ltd.). The analysis revealed that AEP contained the following acids: $13.5 \%$ 4,5-dicaffeoylquinic, 13.4\% 3,5-dicaffeoylquinic, $4.9 \%$ p-coumaric, $1.7 \%$ chlorogenic, 1.3\% 3,4-dicaffeoylquinic, $0.6 \%$ 4-caffeoylquinic, $0.2 \% 3$-caffeoylquinic and $0.2 \%$ caffeic. The main ingredients of EEP were artepillin C (17.3\%) and (E)-3-prenyl-4(2,3-dihydrocinnamoyloxy) cinnamic acid $(11.8 \%)$. We were not able to determine chemistry of other components in EEP.

Animals, chemicals and diets. Male Wistar Hannover (GALAS) rats (19) aged 4 weeks purchased from CLEA Japan, Inc. (Tokyo, Japan) were used in the ACF assay. The animals were maintained in the Kanazawa Medical University Animal Facility according to the Institutional Animal Care Guidelines. The animals were housed in plastic cages (4 rats/ cage) with free access to drinking water and a basal diet, CRF-1 (Oriental Yeast Co., Ltd., Tokyo, Japan) under controlled conditions of humidity $(50 \pm 10 \%)$, lighting (12-h light/dark cycle) and temperature $\left(23 \pm 2^{\circ} \mathrm{C}\right)$. The animals were quarantined for 7 days after arrival and randomized by body weight into experimental and control groups (Fig. 1). Beginning at 5 weeks of age, they were fed with experimental diets for 4 weeks. The rats in groups 1 (11 rats) and 9 (4 rats) were fed the basal diet alone. Groups 2-4 (8 rats each) were fed the diets containing 100, 500 and 1,000 ppm of AEP, respectively. Groups 5 and 6 ( 8 rats each) were given the diets containing 500 and 1,000 ppm of EEP, respectively. Groups 7 and 8 (4 rats each) were fed the diets containing $1000 \mathrm{ppm}$ of AEP and EEP alone, respectively. All rats were freely available for the experimental and basal diets and tap water, and weighed weekly. At 6 weeks of age, the animals in groups 1-6 were given two subcutaneous injections of 
Table I. Body, liver and relative liver weights.

\begin{tabular}{llcccc}
\hline Group no. & Treatment & $\begin{array}{c}\text { No. of rats } \\
\text { examined }\end{array}$ & Body weight $(\mathrm{g})$ & Liver weight $(\mathrm{g})$ & $\begin{array}{c}\text { Relative liver weight } \\
\text { (g/100 g body weight) }\end{array}$ \\
\hline 1 & AOM & 11 & $266 \pm 22^{\mathrm{a}}$ & $12.3 \pm 2.8$ & $4.59 \pm 0.70$ \\
2 & AOM+AEP $(100 \mathrm{ppm})$ & 8 & $263 \pm 11$ & $13.6 \pm 1.3$ & $5.17 \pm 0.39$ \\
3 & AOM+AEP $(500 \mathrm{ppm})$ & 8 & $255 \pm 15$ & $12.1 \pm 1.1$ & $4.71 \pm 0.25$ \\
4 & AOM+AEP $(1000 \mathrm{ppm})$ & 8 & $255 \pm 16$ & $12.9 \pm 1.6$ & $5.03 \pm 0.39$ \\
5 & AOM+EEP $(500 \mathrm{ppm})$ & 8 & $260 \pm 15$ & $13.1 \pm 1.6$ & $5.03 \pm 0.39$ \\
6 & AOM+EEP $(1000 \mathrm{ppm})$ & 8 & $253 \pm 14$ & $12.0 \pm 0.9$ & $4.72 \pm 0.24$ \\
7 & AEP $(1000 \mathrm{ppm})$ & 4 & $253 \pm 13$ & $11.8 \pm 1.3$ & $4.62 \pm 0.31$ \\
8 & EEP $(1000 \mathrm{ppm})$ & 4 & $252 \pm 3$ & $12.9 \pm 0.6$ & $5.10 \pm 0.26$ \\
\hline
\end{tabular}

${ }^{\mathrm{a}}$ Means $\pm \mathrm{SD}$

AOM (20 mg/kg body weight, Sigma-Aldrich Chemical Co., St. Louis, MO, USA) to induce ACF. The animals were sacrificed 2 weeks after the last administration of AOM, and complete necropsies were performed. Eight rat colons from group 1 and 5 rat colons each from groups 2-9 were subjected to determine the presence of ACF.

Determination of ACF. The number of ACF per colon was determined according to the method described in our previous report (20). At autopsy, the colons were flushed with saline, excised, cut open longitudinally along the main axis and then washed with saline. They were cut, and fixed in $10 \%$ buffered formalin for at least $24 \mathrm{~h}$. Fixed colons were dipped in a $0.5 \%$ solution of methylene blue in distilled water for $30 \mathrm{sec}$, briefly washed with the distilled water, and placed on microscope slides with the mucosal surface up. Using a light microscope (Olympus BX41, Olympus Optical Co., Ltd., Tokyo, Japan) at a magnification of $\mathrm{x} 40$, ACF were counted. After counting ACF, the colonic tissues were routinely processed for tissue preparation for histopathology and immunohistochemistry.

Immunohistochemistry. Immunohistochemistry for the proliferating cell nuclear antigen (PCNA) and apoptotic nuclei was performed on $4-\mu \mathrm{m}$ thick paraffin-embedded sections from the rat colons in each group by the labeled streptavidin biotin method using an LSAB kit (Dako Japan, Kyoto, Japan) with microwave accentuation. The paraffinembedded sections were heated for $30 \mathrm{~min}$ at $65^{\circ} \mathrm{C}$, deparaffinized in xylene, and rehydrated through graded ethanol at room temperature. Tris $\mathrm{HCl}$ buffer $(0.05 \mathrm{M}, \mathrm{pH} 7.6)$ was used to prepare solutions and for washes between various steps. Incubations were performed in a humidified chamber. To determine the PCNA-incorporated nuclei, PCNA immunohistochemistry was performed according to the method described by Watanabe et al (21). The apoptotic index was also evaluated by immunohistochemistry for single-stranded DNA (ssDNA) (21). Sections were treated for $40 \mathrm{~min}$ at room temperature with $2 \% \mathrm{BSA}$ and incubated overnight at $4^{\circ} \mathrm{C}$ with primary antibodies. These antibodies included anti-PCNA mouse monoclonal antibody (diluted 1:50, PC10, Dako Japan), and anti-ssDNA rabbit polyclonal antibody (diluted 1:300, Dako Japan). Horseradish peroxidase activity was visualized by treatment with $\mathrm{H}_{2} \mathrm{O}_{2}$ and 3,3'-diaminobenzidine for $5 \mathrm{~min}$. At the final step, the sections were weakly counterstained with Mayer's hematoxylin (Merck Ltd., Tokyo, Japan). For each case, negative controls were performed on serial sections. On the control sections, incubation with the primary antibodies was omitted. The intensity and localization of immunoreactivity against the two primary antibodies used were examined on all sections using a microscope, Olympus BX41 (Olympus Optical Co., Ltd.). The PCNA and apoptotic indices were determined by counting the number of positive nuclei at least 100 cells each in the lesional or normal-appearing crypts, and were expressed as percentages.

Statistical analysis. All measurements were statistically analyzed using one-way ANOVA followed by Tukey-Kramer post-hoc test for multiple comparison test (GraphPad Instat version 3.05, GraphPad Softwear, San Diego, CA, USA). Differences were considered to be statistically significant at $\mathrm{P}<0.05$.

\section{Results}

Table I shows the body, liver and relative liver weights of the rats in all groups. The animals remained healthy throughout the experimental period. The mean body, liver and relative liver weights did not significantly differ among the groups.

Frequency of ACF. Table II summarizes the data of the colonic $\mathrm{ACF}$ analysis. The rats belonging to groups 1-6 that received AOM, developed ACF (Fig. 2a and b). ACF were not observed in rats in groups 7-9 that were not administered $\mathrm{AOM}$. The mean number of $\mathrm{ACF} /$ colon of group 1 was 38.8 \pm 19.9 . The dietary administration of AEP and EEP at all the dose levels caused significant inhibition of ACF formation: 100 ppm AEP, 14.2 \pm 5.2 (63\% reduction, $\mathrm{P}<0.01$ ); 500 ppm AEP, $8.8 \pm 8.7$ (77\% reduction, $\mathrm{P}<0.01$ ); 1,000 ppm AEP, $10.6 \pm 6.9$ (73\% reduction, $\mathrm{P}<0.01) ; 500 \mathrm{ppm}$ EEP, 7.2 \pm 5.4 
Table II. Effects of AEP and EEP of the extracts from propolis on AOM which induces ACF in rat colons.

\begin{tabular}{|c|c|c|c|c|c|c|}
\hline $\begin{array}{l}\text { Group } \\
\text { no. }\end{array}$ & Treatment & $\begin{array}{l}\text { No. of rats } \\
\text { examined }\end{array}$ & $\begin{array}{l}\text { No. of } \mathrm{ACF} / \\
\text { colon }\end{array}$ & $\begin{array}{c}\text { No. of ACF consisted } \\
\text { of }>4 \text { crypts/colon }\end{array}$ & $\begin{array}{l}\text { Total no. of aberrant } \\
\text { crypts (ACs)/colon }\end{array}$ & ACs/focus \\
\hline 1 & $\mathrm{AOM}$ & 8 & $38.8 \pm 19.9^{a}$ & $9.5 \pm 7.8$ & $109.5 \pm 78.6$ & $2.65 \pm 0.90$ \\
\hline 2 & $\mathrm{AOM}+\mathrm{AEP}(100 \mathrm{ppm})$ & 5 & $14.2 \pm 5.2^{\mathrm{b}}$ & $0.2 \pm 0.4^{\mathrm{b}}$ & $18.0 \pm 8.2^{\mathrm{b}}$ & $1.25 \pm 0.21^{\mathrm{c}}$ \\
\hline 3 & $\mathrm{AOM}+\mathrm{AEP}(500 \mathrm{ppm})$ & 5 & $8.8 \pm 8.7^{b}$ & $0^{\mathrm{b}}$ & $11.2 \pm 11.4^{\mathrm{b}}$ & $1.25 \pm 0.28^{\mathrm{c}}$ \\
\hline 4 & $\mathrm{AOM}+\mathrm{AEP}(1000 \mathrm{ppm})$ & 5 & $10.6 \pm 6.9^{b}$ & $0.2 \pm 0.4^{b}$ & $16.0 \pm 11.2^{\mathrm{b}}$ & $2.51 \pm 0.13$ \\
\hline 5 & $\mathrm{AOM+EEP} \mathrm{(500} \mathrm{ppm)}$ & 5 & $7.2 \pm 5.4^{\mathrm{c}}$ & $0^{\mathrm{b}}$ & $9.6 \pm 7.8^{b}$ & $1.31 \pm 0.27^{\mathrm{c}}$ \\
\hline 6 & AOM+EEP (1000 ppm) & 5 & $6.4 \pm 4.3^{\mathrm{c}}$ & $0^{\mathrm{b}}$ & $7.6 \pm 5.6^{\mathrm{b}}$ & $1.41 \pm 0.16^{\mathrm{c}}$ \\
\hline
\end{tabular}

${ }^{\mathrm{a}}$ Means $\pm \mathrm{SD} .{ }^{\mathrm{b}, \mathrm{c}}$ Significantly different from group 1 by Tukey-Kramer multiple comparison test $\left({ }^{\mathrm{b}} \mathrm{P}<0.01\right.$ and $\left.{ }^{\mathrm{c}} \mathrm{P}<0.001\right)$.

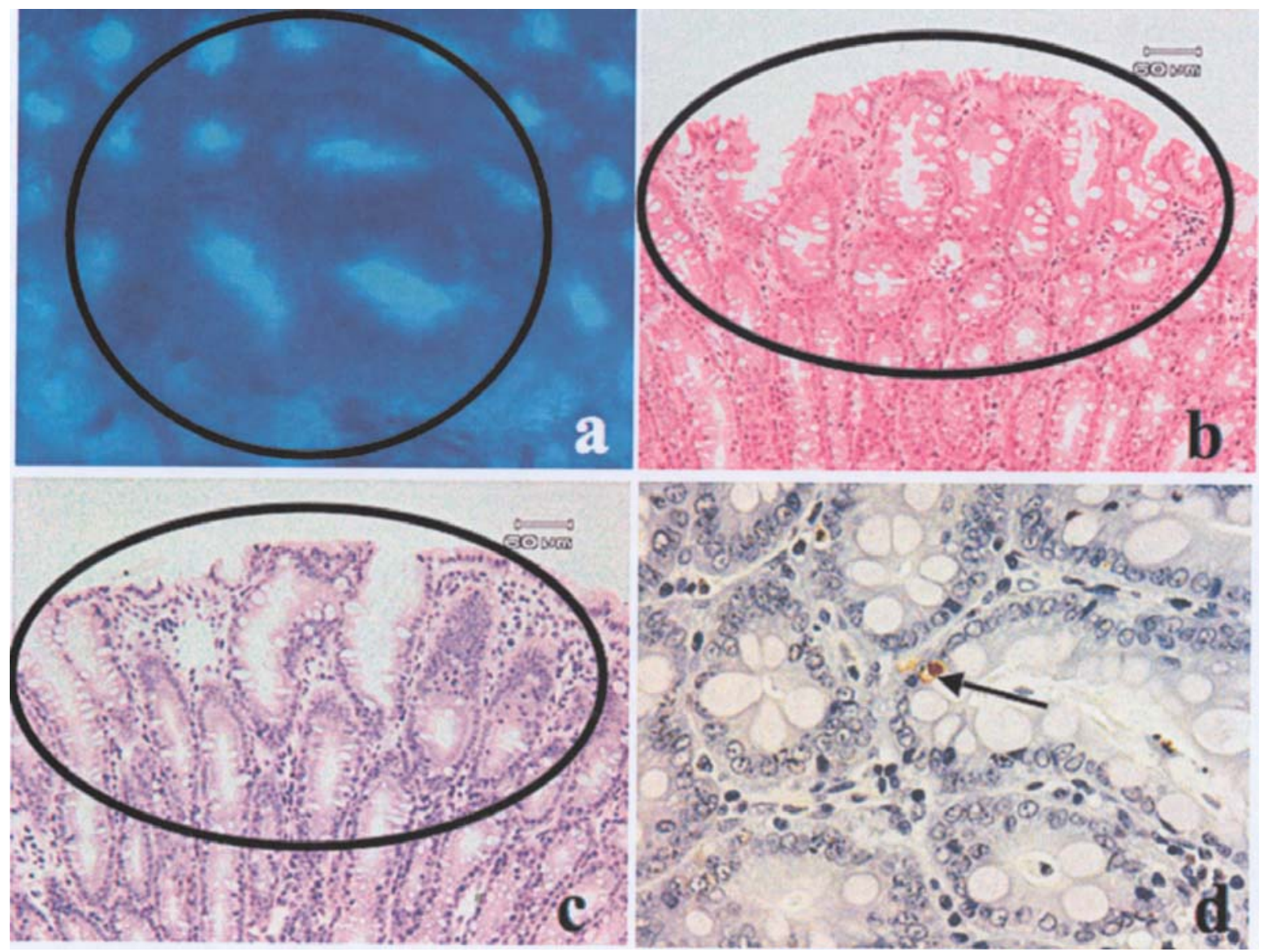

Figure 2. Histopathology and immunohistochemistry of PCNA and ssDNA. (a) ACF (circled) stained by methylene blue consisting of three aberrant crypts (group 1); (b) ACF (circled) stained with hematoxylin and eosin consisting of five aberrant crypts (group 1); (c) PCNA immunohistochemistry of ACF consisting of five aberrant crypts and (d) ssDNA immunohistochemistry of non-lesional crypts. The arrow indicates an ssDNA-positive nucleus (apoptotic nucleus). Original magnification: (a) x20; (b) x50; (c) x50 and (d) x200.

(81\% reduction, $\mathrm{P}<0.001)$ and $1,000 \mathrm{ppm} \mathrm{EEP}, 6.4 \pm 4.3(84 \%$ reduction, $\mathrm{P}<0.001)$. There were significant decreases in the total number of aberrant crypts $(\mathrm{ACs})$ per colon $(\mathrm{P}<0.01)$ in groups 2-6, and the number of $A C s$ per focus $(\mathrm{P}<0.01)$ in these groups except for group 4. The numbers of ACF consisting of $>4$ crypts in groups 2-6 were significantly smaller than that of group $1(\mathrm{P}<0.01)$.

PCNA-labeling index. The PCNA-labeling index in the ACF (Fig. 2c) and normal-appearing crypts are presented in
Table III. As for the mean PCNA-labeling index of ACF, the values of groups $3(18.4 \pm 3.0, \mathrm{P}<0.001)$ and $4(14.0 \pm 1.6$, $\mathrm{P}<0.001$ ), which were treated with 500 and $1,000 \mathrm{ppm}$ of AEP, respectively, were significantly decreased when compared with group 1 (26.6 \pm 3.6$)$, although group $2(21.4 \pm 2.1)$, which was treated with $100 \mathrm{ppm}$ AEP, was insignificantly reduced. The indices of groups $5(13.4 \pm 2.1, \mathrm{P}<0.001)$ and $6(12.2 \pm 4.2$, $\mathrm{P}<0.001)$, which were treated with 500 and $1,000 \mathrm{ppm}$ of EEP alone, respectively, were significantly reduced when compared with group 1 . The mean PCNA-labeling indices in 
Table III. PCNA-labeling and apoptotic index in ACF and colonic crypts of rats treated with AOM and/or AEP and EEP of the extracts from propolis.

\begin{tabular}{|c|c|c|c|c|c|}
\hline \multirow[b]{2}{*}{ Group no. } & \multirow[b]{2}{*}{ Treatment } & \multicolumn{2}{|c|}{ PCNA-labeling index $(\%)$} & \multicolumn{2}{|c|}{ Apoptosis index (\%) } \\
\hline & & $\mathrm{ACF}$ & Normal-appearing crypt & $\mathrm{ACF}$ & Normal-appearing crypt \\
\hline 1 & $\mathrm{AOM}$ & $\begin{array}{c}26.6 \pm 3.6^{\mathrm{a}} \\
(8)\end{array}$ & $\begin{array}{c}19.1 \pm 2.0 \\
(8)\end{array}$ & $\begin{array}{c}4.1 \pm 0.8 \\
(8)\end{array}$ & $\begin{array}{c}0.47 \pm 0.11 \\
(8)\end{array}$ \\
\hline 2 & AOM+AEP (100 ppm) & $\begin{array}{c}21.4 \pm 2.1 \\
(5)\end{array}$ & $\begin{array}{c}16.0 \pm 3.2 \\
(5)\end{array}$ & $\begin{array}{c}4.8 \pm 2.4 \\
(5)\end{array}$ & $\begin{array}{c}0.49 \pm 0.12 \\
(5)\end{array}$ \\
\hline 3 & $\mathrm{AOM}+\mathrm{AEP}(500$ ppm) & $\begin{array}{c}18.4 \pm 3.0^{\mathrm{b}} \\
(5)\end{array}$ & $\begin{array}{c}12.4 \pm 2.7^{b} \\
(5)\end{array}$ & $\begin{array}{c}6.4 \pm 2.7 \\
(5)\end{array}$ & $\begin{array}{c}0.46 \pm 0.19 \\
(5)\end{array}$ \\
\hline 4 & $\mathrm{AOM}+\mathrm{AEP}(1000 \mathrm{ppm})$ & $\begin{array}{c}14.0 \pm 1.6^{\mathrm{b}, \mathrm{c}} \\
(5)\end{array}$ & $\begin{array}{c}12.8 \pm 1.9^{b} \\
(5)\end{array}$ & $\begin{array}{c}5.8 \pm 1.5 \\
(5)\end{array}$ & $\begin{array}{c}0.48 \pm 0.13 \\
(5)\end{array}$ \\
\hline 5 & $\mathrm{AOM+EEP} \mathrm{(500} \mathrm{ppm)}$ & $\begin{array}{c}13.4 \pm 2.1^{\mathrm{b}} \\
(5)\end{array}$ & $\begin{array}{c}11.2 \pm 2.3^{\mathrm{b}} \\
(5)\end{array}$ & $\begin{array}{c}6.2 \pm 1.8 \\
(5)\end{array}$ & $\begin{array}{c}0.49 \pm 0.10 \\
(5)\end{array}$ \\
\hline 6 & AOM+EEP (1000 ppm) & $\begin{array}{c}12.2 \pm 4.2^{b} \\
(5)\end{array}$ & $\begin{array}{c}10.4 \pm 2.2^{b} \\
(5)\end{array}$ & $\begin{array}{c}6.6 \pm 1.5 \\
(5)\end{array}$ & $\begin{array}{c}0.48 \pm 0.15 \\
\quad(5)\end{array}$ \\
\hline 7 & AEP (1000 ppm) & - & $\begin{array}{c}9.4 \pm 1.1^{\mathrm{b}} \\
(5)\end{array}$ & - & $\begin{array}{c}0.40 \pm 0.18 \\
\text { (5) }\end{array}$ \\
\hline 8 & EEP (1000 ppm) & - & $\begin{array}{c}9.4 \pm 1.8^{\mathrm{b}} \\
(5)\end{array}$ & - & $\begin{array}{c}0.38 \pm 0.11 \\
(5)\end{array}$ \\
\hline 9 & None & - & $\begin{array}{c}9.8 \pm 1.5^{b} \\
(5)\end{array}$ & - & $\begin{array}{c}0.37 \pm 0.14 \\
\text { (5) }\end{array}$ \\
\hline
\end{tabular}

The numbers in parentheses indicate the number of rats examined. ${ }^{\mathrm{a} M e a n s} \pm \mathrm{SD}$. ${ }^{\mathrm{b}}$ Significantly different from group 1 by Tukey-Kramer multiple comparison test $\left({ }^{b} \mathrm{P}<0.001\right) .{ }^{\mathrm{c}, \mathrm{d}}$ Significantly different from group 2 by Tukey-Kramer's multiple comparison test $\left({ }^{\mathrm{c}} \mathrm{P}<0.01\right)$.

normal-appearing crypts of groups 1-6 were higher than those of groups 7-9. Dietary feeding with AEP and EEP at all doses, except for group 2, significantly reduced the mean PCNA-labeling indices when compared with group 1 $(\mathrm{P}<0.001)$.

Apoptotic index. The mean apoptotic indices in ACF (Fig. 2d) and normal-appearing crypts are presented in Table III. The mean apoptotic indices increased by treatment with AEP or EEP, but did not significantly differ among the groups.

\section{Discussion}

In the present study, we demonstrated that aqueous (AEP) and ethanolic fractions (EEP) extracted from Brazilian propolis exerted an inhibitory effect on ACF formation. Feeding with AEP and EEP decreased the number of large ACF which reflects colon cancer development (22).

In this study, dietary AEP significantly suppressed the ACF formation induced by AOM, but the effect was not dosedependent. Our findings, however, suggest that $500 \mathrm{ppm}$ of AEP is the optimum dose to exert its ACF-inhibiting effect. Noteworthy findings in this study are that feeding with AEP as well as EEP was able to lower the cell proliferation activity in the ACF and their surrounding normal-appearing crypts, but did not affect apoptosis. de Lima et al reported that the aqueous extract of Brazilian propolis can modulate the DNA damage induced by DMH (23). When the effects of AEP were evaluated on the formation of DMH-induced ACF and DNA damage in the colon of male Wistar rats by the $\mathrm{ACF}$ and Comet assays, respectively, AEP showed no statistically significant reduction of ACF either simultaneously with or after DMH treatment. However, AEP administered simultaneously with DMH, reduced DNA damage induction in the mid and distal colon. The difference of the effects of AEP of ACF formation between their study and our study may be due to the difference of strain of rats used. A water extract of Brazilian green propolis has recently been reported to inhibit doxorubicin-induced somatic mutation (24). Our study demonstrated that chrysin, present in an ethanolic extract of propolis, has a chemopreventive activity in ACF occurrence in rats initiated with AOM (25). Taken together, propolis extracts, either aqueous or ethanolic, affect proliferation and result in the inhibition of ACF development.

Several studies have indicated anticarcinogenic activity of propolis in the colon. Dietary propolis significantly reduced the number of colonic ACF induced by 1,2-dimethylhydrazine $(\mathrm{DMH})$ in rats (13). Caffeic acid esters, which are present in the ethanolic extract of propolis, suppressed ACF induced by $\mathrm{AOM}$ and inhibited the activities of ornithine decarboxylase, 
tyrosine protein kinase, and lipoxygenase in the colon and liver (14). Among the constituents of propolis, artepillin $\mathrm{C}$ is considered to be responsible for the anticancer property of propolis. Artepillin C induces cell-cycle arrest via stimulation of Cip1/p21 expression in the human colon cancer cells, Caco-2 (26). Dietary artepillin C also suppresses ACF development in conjunction with the induction of phase II enzymes in liver in mice initiated with AOM (15). Although several reports exist demonstrating the cancer chemopreventive effects of other ingredients in propolis, such as caffeic acid ester (14,27), cinnamic acid (28) and galagin (29), few experiments investigating the chemopreventive ability of propolis extracts or fractions exist.

In the AEP used in this study, the main ingredients are dicaffeoylquinic acid isomers, $p$-coumaric acid and chlorogenic acid as reported previously (30). Notably, 3,4-, 3,5- and 4,5$\mathrm{di}-O$-dicaffeoylquinic acid isolated from the sweet potato (Ipomoea batatas L.) possesses anti-mutagenic activity in the reverse mutation of Salmonella typhimurium TA 98 induced by the 3-amino-1,4-dimethyl-5H-pyrido(4,3-b) indole (17). A water extract of Brazilian green propolis and its main ingredients of caffeoylquinic acid derivatives (3,4-di- $O$ caffeoylquinic, 3,5-di- $O$-caffeoyl-quinic and chlorogenic acids), have antioxidant effects (16). Although dicaffeoylquinic acid possesses antioxidant activity $(31,32)$, its chemopreventive effects of carcinogenesis have yet to be reported. $p$-Coumaric acid with antioxidative ability (33) inhibits cell proliferation by affecting cell cycle phases in the human colonic cell line Caco-2 (34), and significantly decreased the mutagenicity of Glu-P-2 (35). Dietary chlorogenic acid, a prominent antioxidant (36), prevents the development of the AOM-induced ACF in rat colon (37) and inhibits DNA methylation in human breast cancer cells (38). Therefore, these biological activities of the main constituent of AEP may contribute to the reduction of ACF formation in this study.

In conclusion, our results suggest that AEP (mainly containing dicaffeoylquinic acid isomers) as well as EEP isolated from the Brazilian propolis exert inhibitory activities against AOM-induced colonic ACF. Their suppressing effects may be due to the suppression of cell proliferation without affecting apoptosis.

\section{Acknowledgements}

This work was supported in part by a Grant-in-Aid for Cancer Research, for the Third-Term Comprehensive 10-Year Strategy for Cancer Control from the Ministry of Health, Labour and Welfare of Japan; a Grant-in-Aid (no. 18880030 to Y.Y., 18592076 to T.T. and 17015016 to T.T.) for Scientific Research from the Ministry of Education, Culture, Sports, Science and Technology of Japan; and grants (S2006-9 to Y.Y. and H2007-12 to T.T.) for the Project Research from the High-Technology Center of Kanazawa Medical University. The authors wish to thank Prof. Toshifumi Hirata, Ph.D. (Department of Mathematical and Life Sciences, Hiroshima University, Japan) for his analysis of extracts of Brazilian propolis.

\section{References}

1. Boring CC, Squires TS and Tong T: Cancer statistics. CA Cancer J Clin 43: 7-26, 1993.

2. Minami Y, Nishino Y, Tsubono Y, Tsuji I and Hisamichi S: Increase of colon and rectal cancer incidence rates in Japan: trends in incidence rates in Miyagi Prefecture, 1959-1997. J Epidemiol 16: 240-248, 2006.

3. Bertram JS, Kolonel LN and Meyskens FL: Rationale and strategies for chemoprevention of cancer in humans. Cancer Res 47: 3012-3031, 1987

4. Boone CW, Kelloff GJ and Malone WE: Identification of candidate cancer chemopreventive agents and their evaluation in animal models and human clinical trials: a review. Cancer Res 50: 2-9, 1990

5. Ivanov T: Composition and physico-chemical properties of propolis. Zhivotnovudni Nauki 17: 96-103, 1980.

6. Volpi N: Separation of flavonoids and phenolic acids from propolis by capillary zone electrophoresis. Electrophoresis 25: 1872-1878, 2004.

7. Kimoto T, Koya S, Hino K, Yamamoto Y, Nomura Y, Micallef MJ, Hanaya T, Arai S, Ikeda M and Kurimoto M: Renal carcinogenesis induced by ferric nitrilotriacetate in mice, and protection from it by Brazilian propolis and artepillin C. Pathol Int 50: 679-689, 2000.

8. Matsuno T, Jung SK, Matsumoto Y, Saito M and Morikawa J: Preferential cytotoxicity to tumor cells of 3,5-diprenyl-4hydroxycinnamic acid (artepillin C) isolated from propolis. Anticancer Res 17: 3565-3568, 1997.

9. Grunberger D, Banerjee R, Eisinger K, Oltz EM, Efros L, Caldwell M, Estevez V and Nakanishi K: Preferential cytotoxicity on tumor cells by caffeic acid phenethyl ester isolated from propolis. Experientia 44: 230-232, 1988

10. Pascual C, Gonzalez R and Torricella RG: Scavenging action of propolis extract against oxygen radicals. J Ethnopharmacol 41: 9-13, 1994

11. Khayyal MT, el-Ghazaly MA and el-Khatib AS: Mechanisms involved in the antiinflammatory effect of propolis extract. Drugs Exp Clin Res 19: 197-203, 1993.

12. Kujumgiev A, Bankova V, Ignatova A and Popov S: Antibacterial activity of propolis, some of its components and their analogs. Pharmazie 48: 785-786, 1993.

13. Bazo AP, Rodrigues MA, Sforcin JM, de Camargo JL, Ribeiro LR and Salvadori DM: Protective action of propolis on the rat colon carcinogenesis. Teratog Carcinog Mutagen 22: 183-194, 2002.

14. Rao CV, Desai D, Simi B, Kulkarni N, Amin S and Reddy BS: Inhibitory effect of caffeic acid esters on azoxymethane-induced biochemical changes and aberrant crypt foci formation in rat colon. Cancer Res 53: 4182-4188, 1993.

15. Shimizu K, Das SK, Baba M, Matsuura Y and Kanazawa K: Dietary artepillin $\mathrm{C}$ suppresses the formation of aberrant crypt foci induced by azoxymethane in mouse colon. Cancer Lett 240: 135-142, 2006.

16. Nakajima Y, Shimazawa M, Mishima S and Hara H: Water extract of propolis and its main constituents, caffeoylquinic acid derivatives, exert neuroprotective effects via antioxidant actions. Life Sci 80: 370-377, 2007.

17. Yoshimoto M, Yahara S, Okuno S, Islam MS, Ishiguro K and Yamakawa O: Antimutagenicity of mono-, di-, and tricaffeoylquinic acid derivatives isolated from sweetpotato (Ipomoea batatas L.) leaf. Biosci Biotechnol Biochem 66: 2336-2341, 2002.

18. Bird RP: Role of aberrant crypt foci in understanding the pathogenesis of colon cancer. Cancer Lett 93: 55-71, 1995

19. Aoyama H, Kikuta M, Shirasaka N, Hojo H, Takahashi KL, Shimizu N, Harigae M, Taguchi F and Teramoto S: Historical control data on reproductive abilities and incidences of spontaneous fetal malformations in Wistar Hannover GALAS rats. Congenit Anom 42: 194-201, 2002.

20. Tanaka T, Kawabata K, Kakumoto M, Makita H, Hara A, Mori H, Satoh K, Hara A, Murakami A, Kuki W, Takahashi Y, Yonei H, Koshimizu K and Ohigashi H: Citrus auraptene inhibits chemically induced colonic aberrant crypt foci in male F344 rats. Carcinogenesis 18: 2155-2161, 1997 .

21. Watanabe I, Toyoda M, Okuda J, Tenjo T, Tanaka K, Yamamoto T, Kawasaki H, Sugiyama T, Kawarada Y and Tanigawa N: Detection of apoptotic cells in human colorectal cancer by two different in situ methods: antibody against single-stranded DNA and terminal deoxynucleotidyl transferase-mediated dUTPbiotin nick end-labeling (TUNEL) methods. Jpn J Cancer Res 90: 188-193, 1999. 
22. Pretlow TP, O'Riordan MA, Somich GA, Amini SB and Pretlow TG: Aberrant crypts correlate with tumor incidence in F344 rats treated with azoxymethane and phytate. Carcinogenesis 13: 1509-1512, 1992.

23. de Lima RO, Bazo AP, Said RA, Sforcin JM, Bankova V, Darros BR and Salvadori DM: Modifying effect of propolis on dimethylhydrazine-induced DNA damage but not colonic aberrant crypt foci in rats. Environ Mol Mutagen 45: 8-16, 2005.

24. Valadares BL, Graf U and Spano MA: Inhibitory effects of water extract of propolis on doxorubicin-induced somatic mutation and recombination in Drosophila melanogaster. Food Chem Toxicol 46: 1103-1110, 2008.

25. Miyamoto S, Kohno H, Suzuki R, Sugie S, Murakami A, Ohigashi $\mathrm{H}$ and Tanaka T: Preventive effects of chrysin on the development of azoxymethane-induced colonic aberrant crypt foci in rats. Oncol Rep 15: 1169-1173, 2006

26. Shimizu K, Das SK, Hashimoto T, Sowa Y, Yoshida T, Sakai T, Matsuura Y and Kanazawa K: Artepillin C in Brazilian propolis induces $\mathrm{G}(0) / \mathrm{G}(1)$ arrest via stimulation of Cip1/p21 expression in human colon cancer cells. Mol Carcinog 44: 293-299, 2005.

27. Xiang D, Wang D, He Y, Xie J, Zhong Z, Li Z and Xie J: Caffeic acid phenethyl ester induces growth arrest and apoptosis of colon cancer cells via the beta-catenin/T-cell factor signaling. Anticancer Drugs 17: 753-762, 2006.

28. Akao Y, Maruyama H, Matsumoto K, Ohguchi K, Nishizawa K, Sakamoto T, Araki Y, Mishima S and Nozawa Y: Cell growth inhibitory effect of cinnamic acid derivatives from propolis on human tumor cell lines. Biol Pharm Bull 26: 1057-1059, 2003.

29. Heo MY, Sohn SJ and Au WW: Anti-genotoxicity of galangin as a cancer chemopreventive agent candidate. Mutat Res 488: 135-150, 2001.
30. Sawaya AC, Tomazela DM, Cunha IB, Bankova VS, Marcucci MC, Custodio AR and Eberlin MN: Electrospray ionization mass spectrometry fingerprinting of propolis. Analyst 129: 739-744, 2004.

31. Kim HJ and Lee YS: Identification of new dicaffeoylquinic acids from Chrysanthemum morifolium and their antioxidant activities. Planta Med 71: 871-876, 2005.

32. Hung TM, Na M, Thuong PT, Su ND, Sok D, Song KS, Seong YH and Bae K: Antioxidant activity of caffeoylquinic acid derivatives from the roots of Dipsacus asper Wall. J Ethnopharmacol 108: 188-192, 2006.

33. Tsai PJ and She CH: Significance of phenol-protein interactions in modifying the antioxidant capacity of peas. J Agric Food Chem 54: 8491-8494, 2006.

34. Janicke B, Onning G and Oredsson SM: Differential effects of ferulic acid and p-coumaric acid on $\mathrm{S}$ phase distribution and length of S phase in the human colonic cell line Caco-2. J Agric Food Chem 53: 6658-6665, 2005.

35. Yamada J and Tomita Y: Antimutagenic activity of caffeic acid and related compounds. Biosci Biotechnol Biochem 60: 328-329, 1996.

36. Jung HA, Park JC, Chung HY, Kim J and Choi JS: Antioxidant flavonoids and chlorogenic acid from the leaves of Eriobotrya japonica. Arch Pharm Res 22: 213-218, 1999.

37. Morishita Y, Yoshimi N, Kawabata K, Matsunaga K, Sugie S, Tanaka $\mathrm{T}$ and Mori H: Regressive effects of various chemopreventive agents on azoxymethane-induced aberrant crypt foci in the rat colon. Jpn J Cancer Res 88: 815-820, 1997.

38. Lee WJ and Zhu BT: Inhibition of DNA methylation by caffeic acid and chlorogenic acid, two common catechol-containing coffee polyphenols. Carcinogenesis 27: 269-277, 2006. 